\title{
Electric and Adsorption Characteristics of Nanocrystalline V-(N, He) Coatings
}

\author{
Alexey G. Guglya, Viktor G. Kolobrodov, and Ruslan L. Vasilenko \\ NSC Kharkov Institute of Physics and Technology, National Academy of Sciences of Ukraine, 1, Akademicheskaya Street, \\ 61108 Kharkov, Ukraine \\ Correspondence should be addressed to Alexey G. Guglya, guglya@kipt.kharkov.ua
}

Received 17 June 2008; Accepted 22 January 2009

Recommended by Alan K. T. Lau

This paper studies the structure, temperature dependences of electric resistance, and adsorption properties of nanoporous threecomponent $\mathrm{V}-(\mathrm{N}, \mathrm{He})$ coatings. The coatings were produced using the technique of ion beam assisted deposition, in particular, deposition of vanadium onto a titanium substrate simultaneously bombarding it with $\mathrm{N}_{2}+\mathrm{He}$ ions of $30 \mathrm{keV}$. It is shown, in contrast to V-N composites that have negative TCR (temperature coefficient of resistance), that the V-(N, He) coatings have negative TCR only in the temperature range of 250 to $350^{\circ} \mathrm{C}$. A specific surface of pores and adsorption characteristics of V-(N, $\mathrm{He}$ ) composites depend on preliminary treatment of a titanium surface. A coating deposited onto an untreated substrate has specific surface of $25.5 \mathrm{~m}^{2} / \mathrm{g}$. The preliminary irradiation of titanium with $\mathrm{N}_{2}+$ He beam up to a dose of $6 \times 10^{17}$ ion $/ \mathrm{cm}^{2} \mathrm{provides}$ the increase in surface area up to $57.6 \mathrm{~m}^{2} / \mathrm{g}$. The preliminary ion bombardment provides a considerable increase in hydrogen adsorption capacity of coatings. Especially, such impact is noticeable at the room temperature, when the amount of hydrogen absorbed by a coating that was applied onto a treated surface is more than three times of that absorbed by a coating that was deposited onto nonexposed titanium.

Copyright ( $\odot 2009$ Alexey G. Guglya et al. This is an open access article distributed under the Creative Commons Attribution License, which permits unrestricted use, distribution, and reproduction in any medium, provided the original work is properly cited.

\section{Introduction}

Presently scientists believe that solid-state hydrogen storage devices used for the vehicles should have high net capacity, short fueling time and low desorption temperature. In this regard proper consideration is given to metal hydrides and chemical hydrides that are used for these purposes though have definite drawbacks due to properties degradation, heavy weight and problems of waste disposal.

Alongside with hydride candidates for hydrogen storage much attention is given to highly porous structures, in particular, carbon-based nanomaterials, fullerenes, glass microspheres and powder materials. Besides, the microporous structures can be created in a form of coatings using plasma technique.

Actually, the presence of a gas component within a deposited flow and a high degree of process nonequilibrium are required to form a porous coating. It was shown recently $[1,2]$ that in case of ion beam assisted deposition the composites with low phase formation Gibbs energy have nanocrystalline structure whose intercrystal space is filled with nanopores. It has also been established that such (VN) structures have high heat-resistance and can withstand temperatures up to $500^{\circ} \mathrm{C}$ and these are not subjected to blister formation at irradiation with helium ions whose dose amounts to $2 \times 10^{17}$ ions $/ \mathrm{cm}^{2}$ [3]. Moreover, such type of treatment provides transformation of a closed porosity into the open one.

On the other hand, many papers are available that study the hydrogen behavior in materials suitable for the first wall of thermonuclear reactor [4-7]. In particular it was established that presence of admixtures in a form of soluble gases within a crystal lattice of structural materials creates conditions for hydrogen capture. The bonding energy, for example for $\mathrm{C}-\mathrm{H}$ pair reaches $2.8 \mathrm{eV}$ [7]. In addition it was shown that helium contained in such materials, especially in the form of vacancy $\mathrm{He}_{n} \mathrm{~V}_{m}$ clusters, also forms a network of active hydrogen bonding centers [8-10]. 
Thus, the above analysis shows that the fine-dispersed admixtures that are present in a coating in the form of soluble and insoluble gases can create in combination with open nanoporosity the conditions for capturing the hydrogen in large amounts.

The purpose of this research is to obtain a porous nanocrystalline vanadium nitride-based coating, to study its structure, electrophysical characteristics, and hydrogen adsorption capacity.

\section{Experimental Technique}

The coatings were created using ion beam assisted deposition plant ARGO-1 [11]. Vanadium was evaporated from electron beam module onto $\mathrm{NaCl}$ monocrystals and onto titanium foil substrate $100 \mu \mathrm{m}$ thick. The films were deposited at simultaneous bombardment with nitrogen and helium ions of $30 \mathrm{keV}$ at gas components ratio 1:1. The ion current density was $1 \times 10^{14} \mathrm{ion} / \mathrm{cm}^{2} \cdot \mathrm{s}$. The substrate temperature was $300^{\circ} \mathrm{C}$. The metal evaporation rate was controlled using quartz resonator removed from an ion bombardment zone and it was equal to $0.1-0.15 \mathrm{~nm} / \mathrm{s}$. The coatings were $100 \mathrm{~nm}$ thick. The resistance was controlled continuously at depositing the coatings and at their further annealing. A coating structure was studied using the electron microscope JEM-100CX.

Prior to applying a coating in order to create vacancy porosity in titanium foil it was bombarded with $\mathrm{N}_{2}+\mathrm{He}$ ions of the same energy in a dose of up to $6 \times 10^{17} \mathrm{ions} / \mathrm{cm}^{2}$ at $300^{\circ} \mathrm{C}$. A specific surface of the pores was measured using the method described in paper [12]. The interaction of hydrogen with a studied material was investigated through measurement of isochors adsorption. A dosed amount of hydrogen was injected from a calibrated capacity into a chamber and dependence of $P$ on $T$ was measured for each fixed amount of gas released into the chamber.

\section{Research Results and Discussion}

The studies of the initial stage of formation of VN composites including temperature coefficient of resistance (TCR) $[1$, 13] showed that the state of their grain boundary as well as TCR sign depend on Gibbs energy value of a given nitride. The Gibbs energy for vanadium nitride is equal to $70 \mathrm{cal} / \mathrm{mol}[14]$. As a result the formation of the given nitride is accompanied by the formation of an ample amount of intercrystal nanopores (Figure 1(a)). The formed nanopores lead to the increase in specific resistance of a nitride and to the appearance of a hopping mechanism of conductivity and as a result of a negative TCR value (Figure 1(b)).

The structure of vanadium films that were deposited at bombardment with mixed $\mathrm{N}_{2}+\mathrm{He}$ beam differs from that shown in Figure 1(a). As a result fcc VN [13] structure formation also takes place. The main difference is that the addition of helium leads to the formation of the equiaxed and fine-dispersed porosity (Figure 2(a)). The average size of pores is equal to $15 \mathrm{~nm}$, while the size of pores in vanadium nitride coatings is equal to $50 \mathrm{~nm}[1]$. The pores in $\mathrm{V}-(\mathrm{N}$,

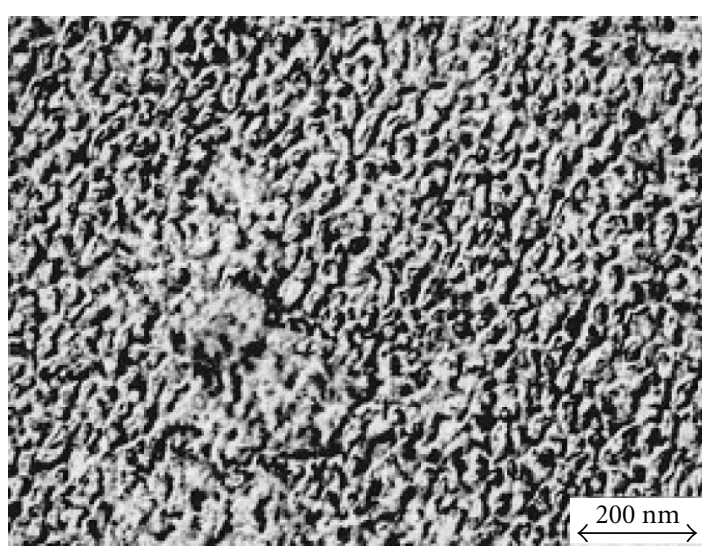

(a)

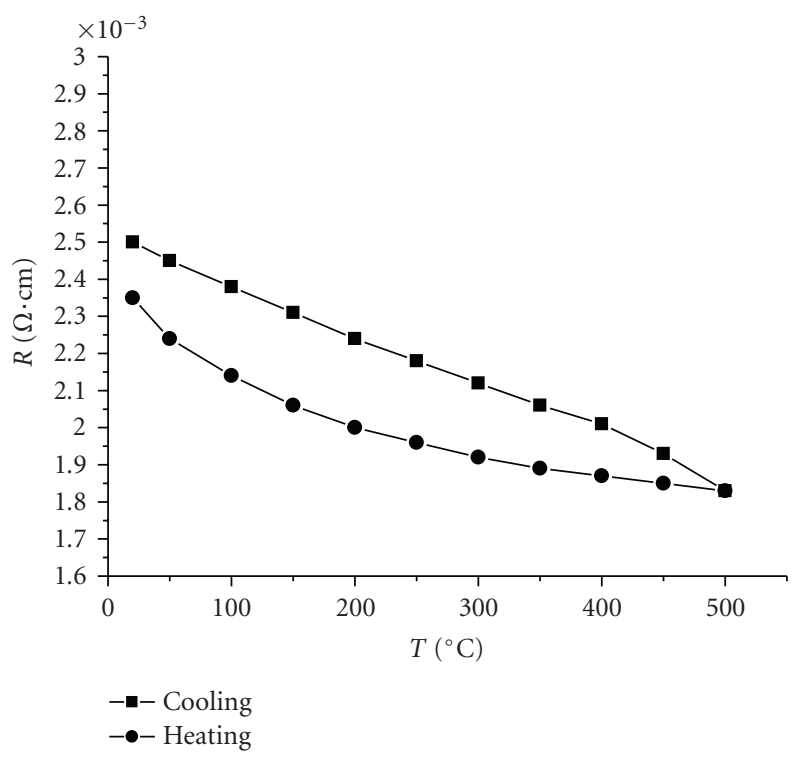

(b)

FIGURE 1: (a) Structure V-N composite; (b) resistivity as a function of temperature.

$\mathrm{He}$ ) composite were evenly distributed across the material thickness.

The increase in the amount of equiaxed internal pores can be explained by presence of helium in a bombarding ion beam. The energy of helium migration in vanadium is not high. It is equal to $0.13 \mathrm{eV}$ [15]. Due to this as the formation of coatings progresses helium leaves the volume of grains and accumulates in triple grain junctions. At the same time the implanted nitrogen will form a vanadium nitride $\mathrm{VN}_{1-x}$ lattice. The availability of pressure inside the gas-filled pores will define their equiaxiality.

Due to the high energy of bombarding gas ions the formation of a structure and phase composition of a coating has a double-stage character. At the stage of nucleation when the surface of grain nuclei contacts the deposited metal atoms the change in their sizes, distribution density and phase composition takes place. At the stage of coating growth whose thickness is within the depth of ion pass 


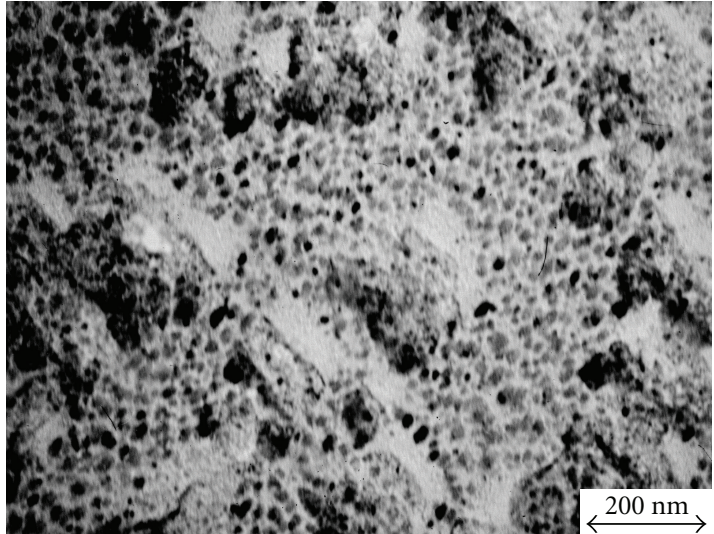

(a)

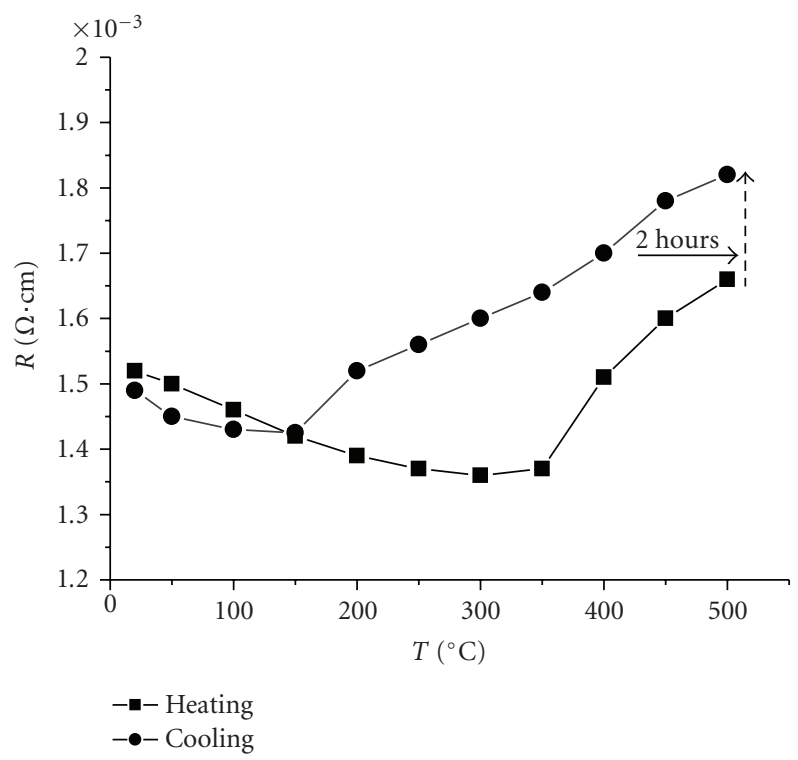

(b)

Figure 2: (a) Structure V-(N, He) composite; (b) resistivity as a function of temperature.

(50 to $80 \mathrm{~nm}$ ) the bombardment is continued and due to this the component composition of a composite also continues to change [16]. At the stage of growth of $\mathrm{V}-(\mathrm{N}, \mathrm{He})$ coating the dangling bonds in a $\mathrm{VN}_{1-x}$ lattice are filled with nitrogen. The helium implanted at vanadium deposition leads to the increase in concentration of gas components in the pores and increases pressure in them.

The availability of gas pores in $\mathrm{V}-(\mathrm{N}, \mathrm{He})$ also leads to the change in dependences of a value of electric resistance on annealing temperature (Figure 2(b)) in comparison with the analogous curves for V-N (Figure 1(b)). A special interest presents the change of TCR sign in the temperature range of 250 to $350^{\circ} \mathrm{C}$. A two-hour annealing at $500^{\circ} \mathrm{C}$ increases the specific resistance in contrast to $\mathrm{V}-\mathrm{N}$ composite. However, at cooling this value returns to the initial one. The electron microscopic study revealed no changes in the material structure. On the other part the change in TCR sign can be explained by the change of electroconductivity mechanism in the studied temperature range.

A hopping mechanism of conductivity prevails in a $\mathrm{VN}_{1-x}$ composite that contains vacancy or near- vacancy pores. In this case the rise in temperature leads to the reduction of electron barriers and to the decrease in electric resistance of materials. As soon as the pores are filled with helium the rise in temperature will inevitably lead to the increase in gas pressure. The pores of $\sim 15 \mathrm{~nm}$ can be described as "imperfect." The relation between a pore radius " $r$ " and pressure " $P$ " in a pore can be described by the expression (see [17])

$$
P=\frac{\mu b}{r}+\frac{2 \gamma}{r}
$$

where $\mu$ is a shear modulus, $b$ is a Burgers vector, and $\gamma$ is a surface energy.

The calculations based on the results of our previous work [11] show that at depositing the $\mathrm{V}-(\mathrm{N}, \mathrm{He})$ coating approximately 10 at. $\%$ of helium are implanted in its lattice. Actually in the long run all helium is condensed in the pores and therefore the internal pressure may reach $10^{3}-10^{4} \mathrm{MPa}$. At annealing with increase in temperature up to $500^{\circ} \mathrm{C}$ the pressure may increase 3 times in comparison with that at a room temperature $[17,18]$. Such increase in pressure will inevitably lead to the increase in stress in the area adjacent to a pore and to the increase in specific electric resistance of a material on the whole, which we observed in our experiments.

The measurement data showed that specific adsorption surface of studied samples was equal to $25.5 \mathrm{~m}^{2} / \mathrm{g}$ for a coating deposited onto unirradiated titanium substrate (sample No1). The specific surface of a coating deposited onto irradiated titanium substrate was $57.6 \mathrm{~m}^{2} / \mathrm{g}$ (sample No2).

A phase composition of a titanium foil that was subjected to a preliminary bombardment with $\mathrm{N}_{2}+\mathrm{He}$ ion beam is a titanium nitride $\left(\mathrm{TiN}_{1-x}\right)$. A crystalline lattice contains equispaced defective areas that have a dark contrast (Figure 3(a)). It is assumed that these areas have helium vacancy clusters of a small size $\left(\mathrm{He}_{n} \mathrm{~V}_{m}, n, m=2-10\right)$. Figure $3(\mathrm{~b})$ shows the simulated curves of distribution of the implanted nitrogen and helium ions. The estimated level of damages in the investigated area is $20 \mathrm{dpa}$ [19].

Figure 4(b) shows experimental $P-T$ dependences at differed hydrogen inlet doses for a sample No1. For the sake of comparison Figure 4(a) shows the analogous dependences for a titanium substrate in its initial state. The $P-T$ plots are characterized by availability of inflection points for all lines of titanium substrate with a coating and without it. It is seen that at interaction of hydrogen with a titanium substrate the temperature at which two straight lines are intersected for each curve is not dependent on pressure value (Figure 4(a)). For substrates with a coating the slope of curves changes at $200^{\circ} \mathrm{C}$ (Figure $\left.4(\mathrm{~b})\right)$ in case of low pressure $(\approx 0.1 \mathrm{MPa})$. With increase of pressure in the chamber the intersection points shift to the area of lower temperatures. From our point of view the presence of an intersection point on $P-T$ line implies the change in interaction mechanism of hydrogen 


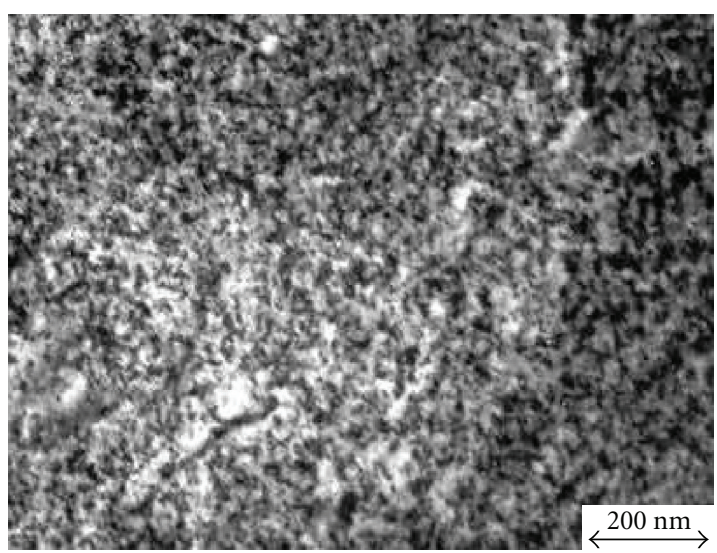

(a)

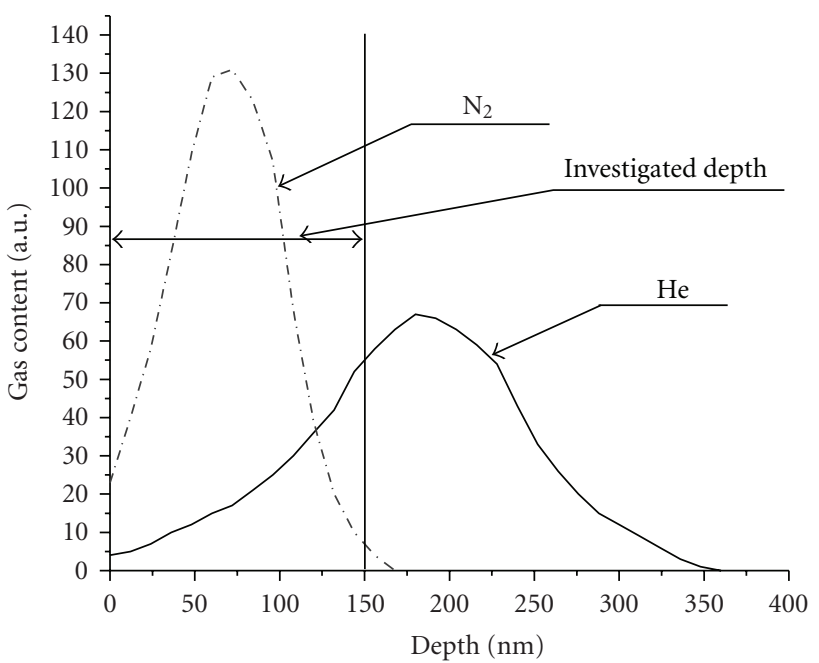

(b)

FIgURE 3: (a) Titanium structure irradiated by $\mathrm{N}_{2}+$ He ions; (b) nitrogen and helium distribution.

and studied material. Possibly, the titanium and porous film structure absorb hydrogen in small amounts at the initial section of curves. Further this absorption is intensified and this can be caused by onset of hydride formation in the intermetallic phase of compounds. The attention should be paid to the fact that with increase in pressure the angle between two straight-line sections of the $P$ - $T$ lines becomes larger and it means that the pressure produces definite impact on formation of these compounds.

Proceed from the $P-T$ dependences the isotherms of hydrogen absorption by the samples No1 and No2 (Figures 5(a) and 5(b)) can be easily calculated. In the studied temperature and pressure ranges the hydrogen strictly obeys the ideal gas laws. For the sake of comparison of different measurement data the value of absorbed hydrogen was reduced to $\mathrm{ncm}^{3} / \mathrm{g}$, that is, to the volume of hydrogen at normal conditions $\left(P=760 \mathrm{~mm} \mathrm{Hg}, T=0^{\circ} \mathrm{C}\right)$.

The figures show that the porous structure plays main role at $20^{\circ} \mathrm{C}$. With increase in pressure up to $\approx 0.175 \mathrm{MPa}$

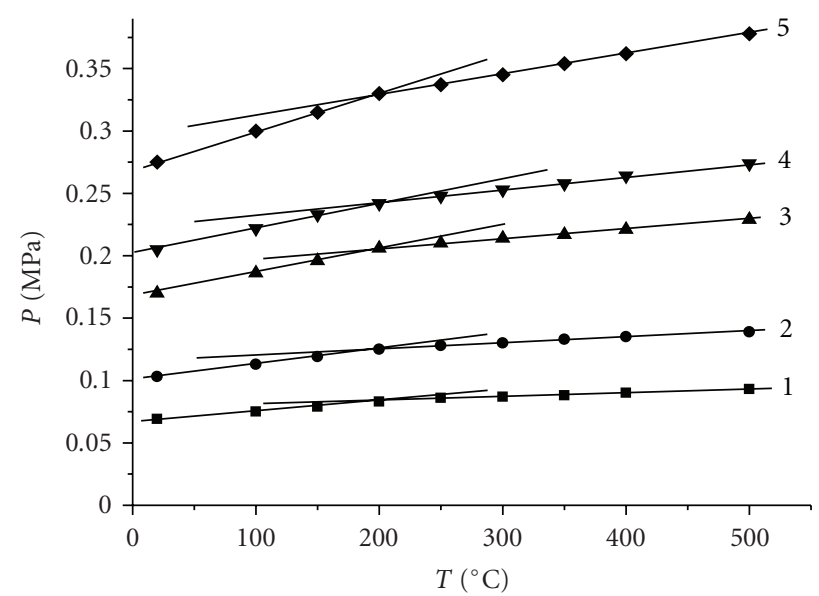

(a)

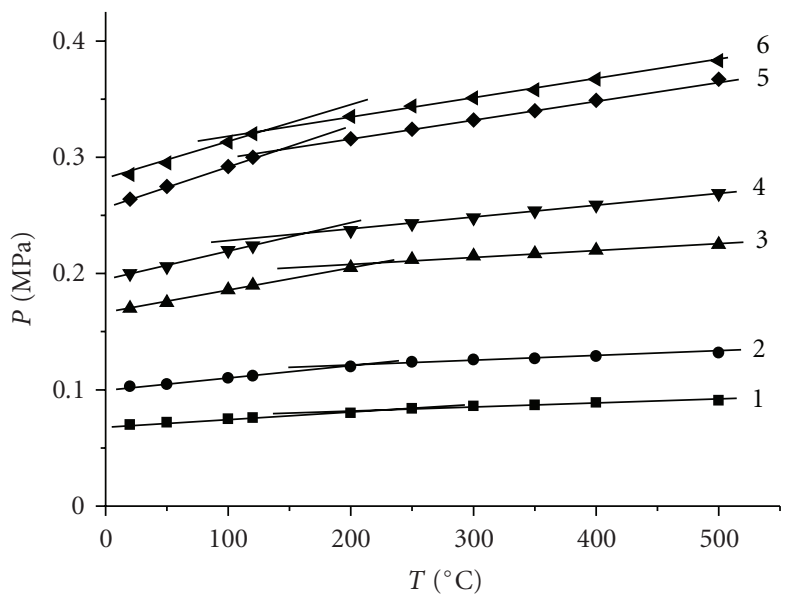

(b)

Figure 4: Pressure in the chamber as a function of temperature for (a) $\mathrm{Ti}$; (b) $\mathrm{Ti}$ with $\mathrm{V}-(\mathrm{N}, \mathrm{He})$ coating for different quantity of hydrogen injection: $1-38.6 \mathrm{ncm}^{3} ; 2-57.9 \mathrm{ncm}^{3} ; 3-95.5 \mathrm{ncm}^{3} ; 4-$ $112.3 \mathrm{ncm}^{3}, 5-155.7 \mathrm{ncm}^{3}, 6-185.2 \mathrm{ncm}^{3}$.

the increase in absorption value is not significant, however at $\approx 0.275 \mathrm{MPa}$ the absorption rate is essentially increasing. At pressure of $\approx 0.3 \mathrm{MPa}$ the hydrogen absorption isotherms reach a saturation level. It should be noted that the isotherm of hydrogen absorption by the sample No2 reaches a saturation level at absorption value that exceeds that for sample No1 actually by factor of 2 . The isotherms of hydrogen absorption by the samples No 1 and 2 are characterized by a higher degree of absorption at temperatures of $300^{\circ} \mathrm{C}$ and $500^{\circ} \mathrm{C}$ in comparison with $20^{\circ} \mathrm{C}$ in the whole pressure interval and the rate of growth of absorption value is increasing in the interval of $0.1 \cdots 0.125 \mathrm{MPa}$. The increase in the rate of growth is more pronounced for the sample No2 that has a larger specific surface.

The obtained data show that the active hydrogen accumulators are the result of the porosity of the coating obtained through the ion beam assisted deposition but also that preliminary created by ion implantation. In addition it should be noted that the activity of the preliminary 


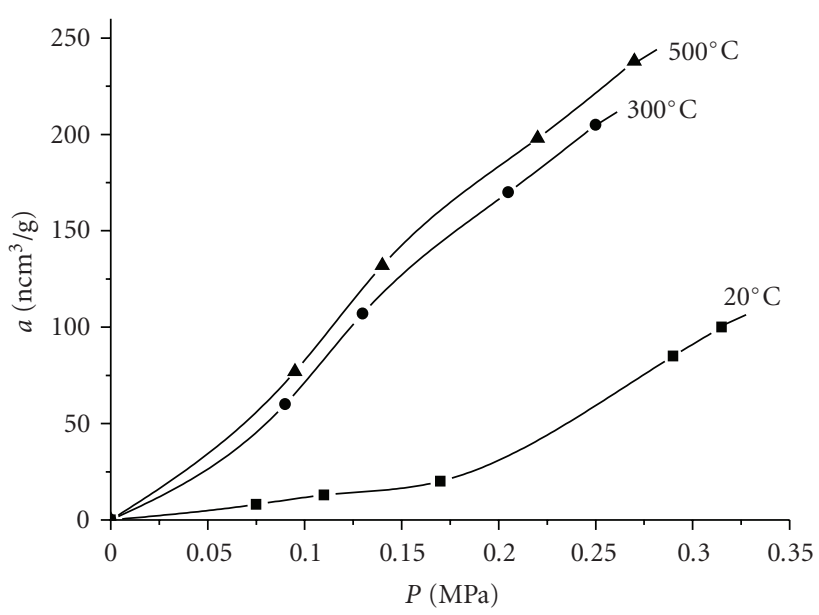

(a)

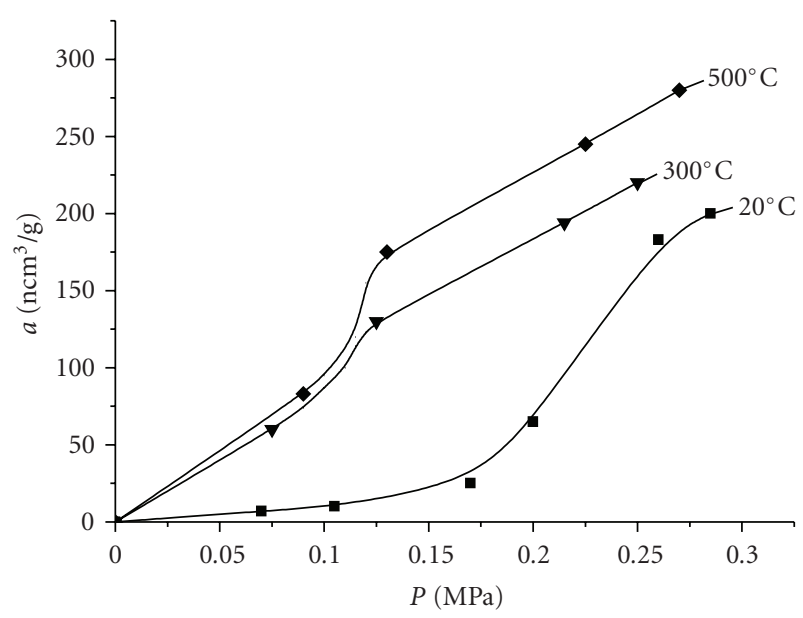

(b)

FIGURE 5: Isotherms of hydrogen adsorption of V-(N, He) coatings on titanium substrate: (a) not irradiated previously, (b) irradiated.

created porosity depends both on the hydrogen temperature and pressure. At low temperatures the implantation based porosity contributes more to hydrogen absorption than at high temperatures (compare Figures 5(a) and 5(b)).

For the comparison the absorption of hydrogen by a titanium substrate at hydrogen pressure of $0.25 \mathrm{MPa}$ is no more then $4.4 \mathrm{ncm}^{3} / \mathrm{g}$. It is seen that the hydrogen-related activity of titanium is much lower in comparison with that of the created porous structures. This means that the porosity of a coating and substrate play a key role in absorption of hydrogen at a room temperature. At a higher temperature the increase in the hydrogen absorption may take place due to two factors, in particular, hydride formation in the intermetallide TiV phases and hydrogen capture with nitride traps that were formed during ion beam assisted deposition of coatings.

\section{Conclusions}

The results of the research show that the ion beam assisted deposition can be used to obtain nanostructural porous structures. The bombardment of the deposited vanadium coating with the mixed beam of nitrogen and helium ions stimulates the formation of nitride phases whose intercrystal spaces contain equiaxial pores. It is quite possible that the volume of pores is occupied by the helium-vacancy clusters. The electric resistance of such materials exceeds that of powder vanadium nitrides by factor of 10. A sign of the temperature coefficient of resistance changes from a negative to the positive one in the temperature range of 250 to $350^{\circ} \mathrm{C}$.

The results of adsorption studies showed that the obtained structures have a rather developed specific surface. It has been established that the main contribution to the process of hydrogen storage at low temperatures is made by the created porous structure. At elevated temperatures the absorption capacity of the intermetallide and nitride phases may increase. The preliminary ion bombardment with the mixed $\mathrm{N}_{2}+$ He beam contributes to the formation of a surface porous layer which is an additional factor contributing to the increase in the adsorption capacity of porous materials.

\section{References}

[1] A. G. Guglya, Nanocrystalline $C r-N$ and $V-N$ coatings. The receiving and investigation, Doctoral thesis, Kharkov Institute of Physics and Technology, Kharkov, Ukraine, 2006.

[2] A. G. Guglya, "Electrophysical and structural and phase charakteristics of thin-film composits $\mathrm{Cr}-\mathrm{N}$ and V-N," The Journal of Kharkov National University, vol. 664, no. 2(27), pp. 73-78, 2005 (Russian).

[3] A. G. Guglya, I. Neklyudov, and R. Vasilenko, "Effect of helium ion irradiation on the structure and electrical resistivity of nanocrystalline Cr-N and V-N coatings," Radiation Effects and Defects in Solids, vol. 162, no. 9, pp. 643-649, 2007.

[4] S. K. Erents, "Deuterium trapping in low-Z coatings," Journal of Nuclear Materials, vol. 111-112, pp. 590-597, 1982.

[5] K. Saiki, H. Tanaka, and S. Tanaka, "Surface composition change of $\mathrm{TiC}$ and $\mathrm{SiC}$ under hydrogen ion bombardment," Journal of Nuclear Materials, vol. 128-129, pp. 744-748, 1984.

[6] K. L. Wilson and A. E. Pontau, "Deuterium trapping and release in titanium-based coatings for TFTR," Journal of Nuclear Materials, vol. 93-94, part 2, pp. 569-574, 1980.

[7] K. Sato, S. Yamaguchi, Y. Fujino, et al., "Deuterium retention in TiC crystals prepared by chemical vapor deposition and floating zone methods," Journal of Nuclear Materials, vol. 128129, pp. 698-702, 1984.

[8] S. T. Picraux, J. Bøttiger, and N. Rud, "Enhanced hydrogen trapping due to He ion damage," Journal of Nuclear Materials, vol. 63, no. 1, pp. 110-114, 1976.

[9] A. E. Pontau, M. I. Baskes, K. L. Wilson, et al., "Deuterium retention in helium-damaged stainless steel: detrapping energy," Journal of Nuclear Materials, vol. 111-112, pp. 651-653, 1982.

[10] R. Schulz, R. Benrisch, and B. M. Scherzer, "Trapping and mutual release of D and $3 \mathrm{He}$ in molybdenum," Journal of Nuclear Materials, vol. 93-94, part 2, pp. 608-616, 1980.

[11] A. G. Guglya, I. G. Marchenko, D. G. Malykhin, and I. M. Neklyudov, "Production of Cr-N films by ion beamassisted deposition technology: experiment and computer 
simulation," Surface and Coatings Technology, vol. 163-164, pp. 286-292, 2003.

[12] S. J. Gregg and K. S. W. Sing, Adsorption, Surface Area, and Porosity, Academic Press, London, UK, 1967.

[13] R. Vasilenko, A. G. Guglya, and M. Litvinenko, "The influence of treatment on conductivity V-N films, received during high energy nitrogen ion bombardment," Metalofisika i Noveishie Tehnologii, vol. 28, no. 9, pp. 1167-1176, 2006 (Russian).

[14] Y. Baba and T. A. Sasaki, "Nitride formation at metal surfaces by $\mathrm{Ar}^{+}$ion bombardment in nitrogen atmosphere," Materials Science \& Engineering A, vol. 115, pp. 203-207, 1989.

[15] W. D. Wilson and R. A. Jonson, Interatomic Potentials and Simulation of Lattice Defects, Plenum Press, London, UK, 1972.

[16] V. I. Bendikov, A. G. Guglya, I. G. Marchenko, D. G. Malykhin, and I. M. Neklyudov, "Mechanisms of forming the Cr-N composite in the unsteady-state stage of ion beam-assisted deposition process," Vacuum, vol. 70, no. 2-3, pp. 331-337, 2003.

[17] H. Trinkaus, "Energetics and formation kinetics of helium bubbles in metals," Radiation Effects and Defects in Solids, vol. 78, no. 1-4, pp. 189-211, 1982.

[18] W. Jäger, R. Manzke, H. Trinkaus, R. Zeller, J. Fink, and G. Crecelius, "The density and pressure of helium in bubbles in metals," Radiation Effects and Defects in Solids, vol. 78, no. 1-4, pp. 315-325, 1982.

[19] J. F. Ziegler, J. P. Biersack, and K. Littmark, The Stopping and Range of Ions in Matter, Pergamon Press, New York, NY, USA, 1985. 

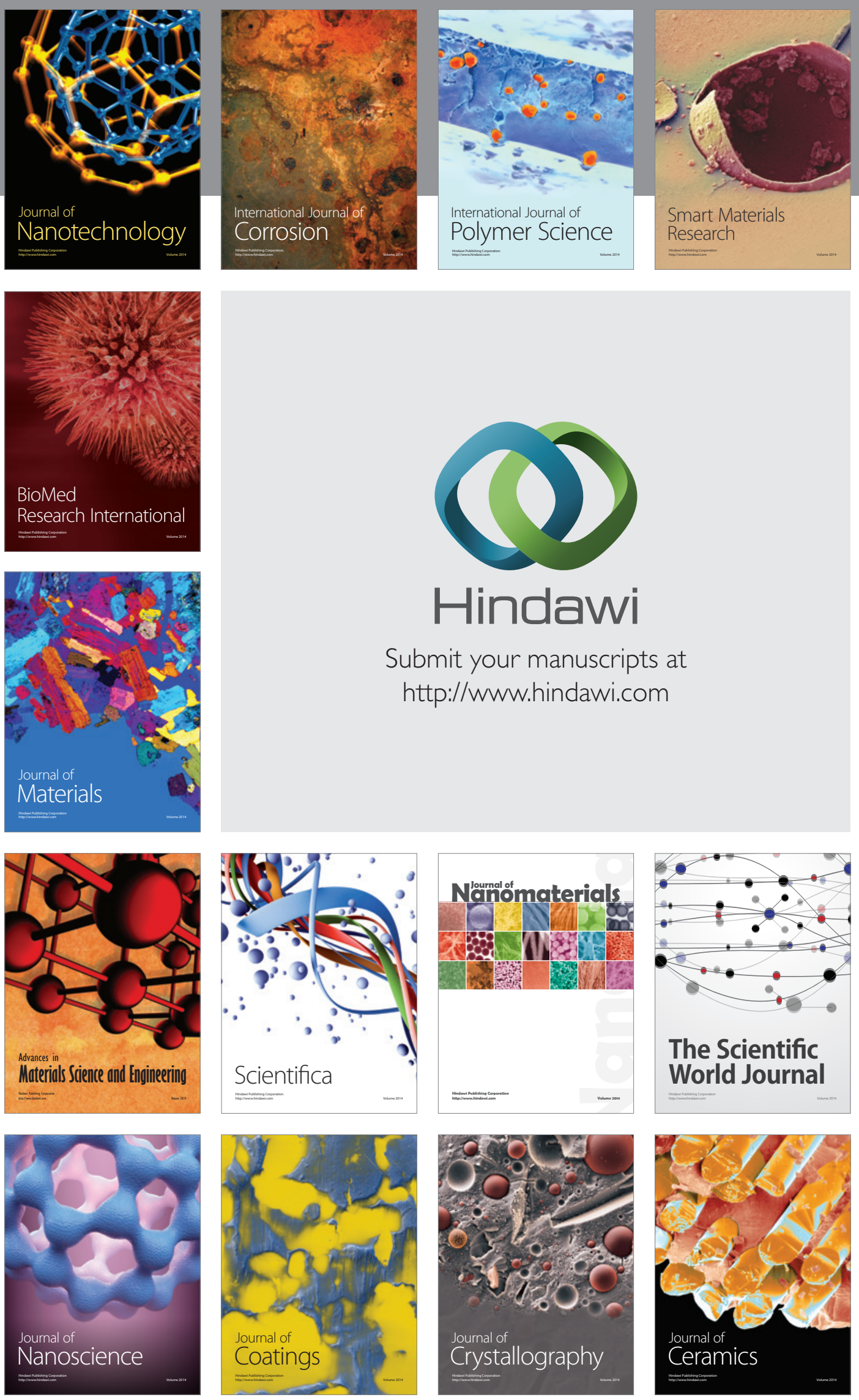

The Scientific World Journal

Submit your manuscripts at

http://www.hindawi.com

\section{World Journal}

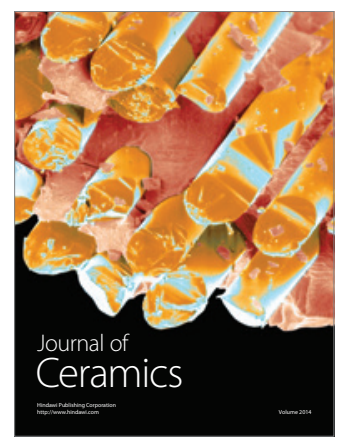

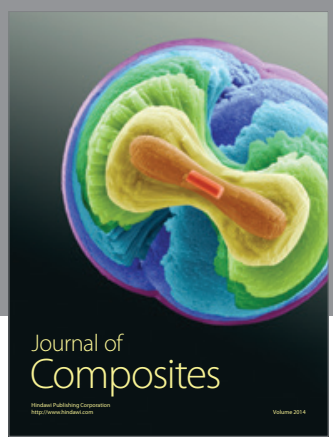
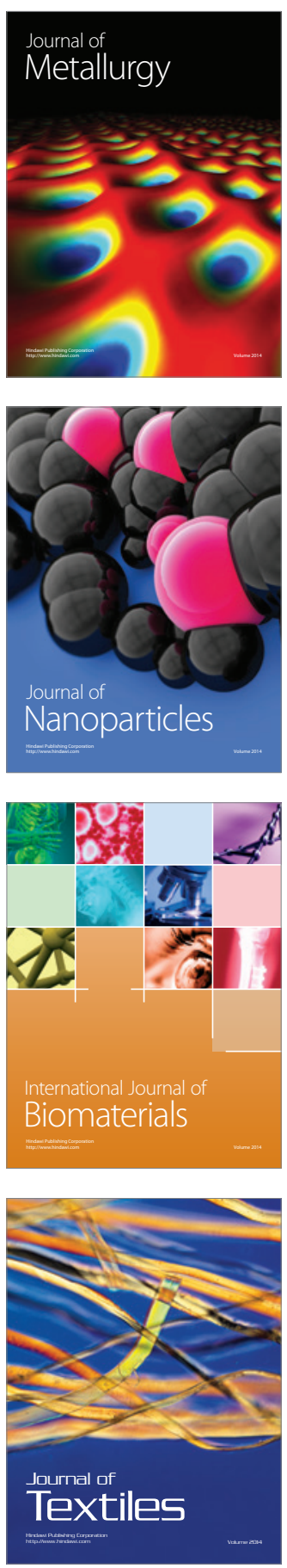